

\title{
Jornal da Tarde, 6 de julho de 1982: a imagem como construção de sentidos de uma derrota
}

\author{
Jornal da Tarde, July 6 th, 1982 : the image as the \\ construction of the senses of a defeat
}

Filipe Fernandes Ribeiro Mostaro*

Ronaldo Helal***

\begin{abstract}
Resumo: O presente artigo analisa o processo de articulação dos sentidos da foto de Reginaldo Manente que construiu a narrativa da derrota brasileira na Copa de 1982. Partiremos de pressupostos que enfatizam o contexto e a "situação social" (GOFFMAN, 1986) em que uma imagem é produzida, destacando seu caráter híbrido e a construção de uma narrativa jornalística no sentido de tentar estabilizar o processo de significação em um ícone.
\end{abstract}

Palavras-Chave: Imagem. Narrativa. Copa de 1982. Jornalismo.

\begin{abstract}
This paper analyzes the process of articulation of senses of the Reginaldo Manentes's photo that built the Brazilian defeat in the World Cup 1982. We start with assumptions that emphasize the context and the "social situation" (GOFFMAN, 1986) in which an image is produced, emphasizing its hybrid character and the construction of a journalistic narrative to try to stabilize the process of signification on an icon.
\end{abstract}

Keywords: Image. Narratives. World Cup 1982. Jornalism.

\footnotetext{
* Doutorando em Comunicação pelo PPGCOM - Uerj com bolsa CAPES.

** Pesquisador do CNPq. Professor do Programa de Pós-Graduação em Comunicação e da Faculdade de Comunicação Social da Universidade do Estado do Rio de Janeiro.
} 


\section{Introdução}

As narrativas da imprensa comumente procuram enquadrar determinados sentidos para facilitar e padronizar a comunicação, sustentando que uma imagem, uma palavra, por exemplo, resumiriam toda uma situação e um contexto. Este papel midiático na formulação de "explicações" e definições do "real" na sociedade é significativo e no campo esportivo procura erigir uma relação com o torcedor baseada em afetos (SODRÉ, 2006). Especificamente neste trabalho vamos analisar a fotografia de Reginaldo Manente publicada na capa do Jornal da Tarde, de São Paulo, no dia 6 de julho de 1982, como um símbolo da derrota brasileira na Copa do Mundo daquele ano. Entendemos que, na tentativa de estabilizar e aglutinar sentidos, a mídia articula determinados significados que acabam sendo reconhecidos por conta do contexto que a Copa do Mundo suscita na sociedade brasileira.

Acreditamos que nesta articulação de elementos como identidades, representações, imaginário e contextos sociais constróise um discurso e uma narrativa. Para delinear como esses elementos estão em interação e edificaram o sentido da fotografia analisada, vamos indicar, na primeira parte do artigo, a importância do futebol na formação cultural do país durante os anos 1930 e como os sentidos proporcionados pela seleção brasileira sugerem a simbiose seleção-nação, fato sedimentado no imaginário nacional ao longo das Copas do Mundo. Essa associação, explicitada pela expressão "pátria de chuteiras" do dramaturgo Nelson Rodrigues, procura deduzir que as vitórias e as derrotas da equipe são interpretadas como fracassos e sucessos da nação como um todo. Além disso, a representação da seleção brasileira de futebol nas narrativas da imprensa infere uma brasilidade intrínseca aos jogadores e à equipe. Esta importância do contexto e da produção de sentidos vinculados a este evento será investigada, principalmente, com base nas ideias de "situação social" em Goffman (1986).

Em seguida, vamos apresentar a conjuntura da derrota da 
seleção brasileira na Copa de 1982 e as narrativas jornalísticas de jornais como $\mathrm{O}$ Globo e Jornal do Brasil, que conduziram o sentido do revés da equipe ao argumento de "tragédia", fato que potencializou os significados da fotografia que será analisada neste artigo. Partimos da ideia de que a imagem dialoga com o contexto no qual ela é produzida e também interpretada. Ao se definir na narrativa da imprensa que a representação da seleção no contexto de Copas do Mundo deve ser a de "vencer sempre" e de "representar milhões de brasileiros", insucessos esportivos funcionam como rupturas nesta representação, indicando um clima de tristeza nos agentes que sustentam e acreditam nela. Entendemos que, neste cenário, a imagem de uma criança chorando, que estampou a capa do Jornal da Tarde, auxilia exatamente no discurso de "fatalidade" construído pela imprensa, tornando-se o ícone que definiria toda a situação. Deste modo, acreditamos que nossa análise contribua para o campo dos estudos da relação esportes e imagem e para a articulação de seus significados na sociedade atual.

\section{A narrativa midiática da "pátria de chuteiras"}

O futebol ocupou um papel determinante na formação da identidade nacional erguida nos anos 1930. Na tentativa de se agrupar elementos que seriam definidos como "nacionais", este esporte e todo seu efeito de mobilização popular, percebidos desde o Campeonato Sul-Americano de 1919 (SARMENTO, 2013), foram incorporados aos pilares que definiriam a identidade nacional. Entendemos a identidade como uma construção social que pretende reunir atributos, características, mitos e crenças de determinados grupos sociais em estereótipos rígidos e coesos, esquecendo a multiplicidade de tais formações. Essas articulações foram eficientes na organização dos Estados-nação na Europa, como destaca Stuart Hall (2011). Ao mesmo tempo em que incutiam valores e sentidos às nações, distinguindo-as e demarcando suas diferenças, legitimavam-se conceitos que antes eram determinados 
por outras instituições, como a Igreja Católica. Essa validação passou a estabelecer o "senso comum"1 sobre determinados assuntos e, neste caso, sobre as nações. Essa elaboração de identidades passa por uma disputa interna entre campos que pretendem se tornar hegemônicos e arquitetam a ideia do que seria o nacional dentro de uma perspectiva que lhe seja favorável.

Essa concepção destaca que as identidades, por mais que procurem estabilizar algo, estão sujeitas a modificações e a reestruturações que dependem de contextos auspiciosos para vigorarem. A própria construção do futebol como identidade nacional encontrou um terreno favorável para propagar as ideias de miscigenação e de democracia racial no Brasil (FREYRE, 2003). Era necessário para os novos grupos sociais em ascensão no país reajustar os sentidos do que viria a ser o nacional. Em um contexto do governo de Getúlio Vargas que, em 1930, encerrou o ciclo da hegemonia das oligarquias cafeeiras e propiciou um crescimento na densidade populacional dos grandes centros, novas acomodações foram sugeridas na formação da identidade brasileira. Nesse quadro, Moscovici (2012) destaca que as representações sociais surgem para tornar familiar o que não era familiar. Sua função seria instaurar uma ordem que possibilitasse às pessoas orientar-se em seu mundo social e controlá-lo, além de fornecer códigos para nomear e classificar, sem ambiguidades, os diversos aspectos da história social e individual (MOSCOVICI, 2012).

Assim, as novas representações sobre o país emergem no sentido de enquadrar determinados aspectos e de descartar outros, privilegiando aquilo que as ideologias vencedoras nos embates

1 A ideia de senso comum será entendida neste trabalho de acordo com a seguinte definição de Sodré $(2009$, p. 45): "senso comum é um nome para o conhecimento daquilo que os gregos chamavam de doxa, isto é, uma experiência da realidade limitada à sensibilidade, às notas acidentais contingentes e variáveis, às representações sociais que reduzem a complexidade factual a imagens de fácil trânsito comunicacional - traduzidas em opinião". Além disso, o senso comum atua como "estabilizador da consciência e mobilizador do pertencimento à comunidade" (SODRÉ, 2009, p. 45). 
internos exaltaram como nacional. A ideia do futebol como símbolo do improviso "tipicamente nacional" e como instrumento de ascensão social dos negros por meio da profissionalização desse esporte, bem como outros elementos como o samba, que também reforçava o lado corporal e mestiço do brasileiro, foram articulados e sustentados como a nossa "essência cultural". Essa cultura nada mais é do que um discurso que visa produzir símbolos e sentidos que vão influenciar e organizar as ações dos indivíduos, proporcionando identificação e construindo identidades (HALL, 2011).

$\mathrm{O}$ que queremos enfatizar é que este enquadramento da representação da miscigenação ${ }^{2}$, e consequentemente do futebol, como algo vinculado ao ethos nacional, tenta estabilizar algo instável. A identidade busca uma definição simples, engessada e direta de algo que pode ser visto por vários ângulos. Para nós, tais enquadramentos sociais de determinados temas e a sua proliferação pelos meios de comunicação penetram no imaginário social de maneira latente, criando mapas culturais sobre a nação que servirão para o sentido de pertencimento, reconhecimento e lealdade dos indivíduos.

Nesta linha de argumentação, a ideia de enquadramento ou framing de Erving Goffman (1986) se torna interessante. Para Goffman, as representações dos indivíduos seguem determinados padrões já previamente estabelecidos e compreendidos pelos que fazem parte daquela sociedade, criando uma "situação social" facilmente identificada. Assim, os frames oferecem definições da realidade social, sendo compartilhados, fundamentados e usados como referência nas culturas onde estão presentes. É, por exemplo, a função de pai, mãe e filho que, de antemão, já esperamos

2 Indicamos que a participação brasileira na Copa do Mundo de 1938, considerada um sucesso (a equipe ficou em terceiro lugar), e as atuações dos jogadores negros como Leônidas da Silva e Domingos da Guia, aliadas ao impacto da transmissão ao vivo pelo rádio, contribuíram para clarificar a ideia romântica de que a nação miscigenada era representada pela seleção de futebol e que esta miscigenação era o motivo do êxito do time, colocando-a como algo positivo. 
comportamentos condizentes àquela representação. Claro que em determinado contexto as representações podem mudar, como o pai, no seu ambiente de trabalho, pode ser empregado e ser subordinado ao chefe, sendo apropriada sua adequação ao novo cenário. O que pretendemos exaltar é que na construção de identidades são postos esses determinados enquadres que suscitam aos atores determinadas funções e ações, que acabam sendo estereotipadas. Desta maneira, o que seria "ser brasileiro"? Gostar de futebol e de samba? Sabemos que não, mas tal enquadramento é realizado constantemente pelos meios de comunicação em situações nas quais a identidade nacional se faz presente.

Alguns momentos servem para reforçar e ressignificar tais identidades. Em sua maioria, são ritualísticos e visam promover o mito da fundação daquela cultura ou identidade. No Brasil, consideramos a Copa do Mundo como o momento apropriado para tal. É comum observarmos campanhas publicitárias que enaltecem nosso futebol como distinto e reafirmam seu papel na constituição da nação. Assim, a seleção brasileira se torna a representante da coletividade, principalmente na metáfora elaborada sobre a competição que seria um "duelo entre nações". Este evento foi se consolidando e permeando o imaginário nacional, construindo uma "situação social" de que o papel desempenhado pela seleção e pelos jogadores é "nos representar" e o "nosso" (brasileiros) é torcermos fervorosamente para que a representação de melhores do mundo se sustente.

A concepção de imaginário é entendida neste trabalho como o ponto de partida da relação e da interação dos demais elementos que compõem uma narrativa. Le Goff (1985) indica que o imaginário circula por meio da história, culturas e dos grupos sociais. O imaginário pode ser entendido como um repertório de imagens, ou um "museu de imagens" como Durand (1997) define, que serão a matéria-prima para se completar ideias e se fazer associações. Precisa-se do imaginário para concluir uma representação e uma narrativa. 
Para Baczko (1985), o que leva o homem a agir é o coração, suas paixões e seus desejos. Para ele é exatamente no imaginário que tais sentimentos são aquecidos por meio do pathos (paixão), que também dirige a linguagem dos símbolos e dos emblemas. Aqui é notório o simbolismo que a seleção brasileira adquiriu ao longo do tempo e a paixão desenvolvida pelo torcedor desde 1938, conforme indica Simoni Guedes (2009), ratificando a importância no imaginário de ela ser a "representante autêntica da nação"3. Estes símbolos se tornaram eficazes por se firmarem no imaginário coletivo nacional, fazendo parte de uma narrativa global do país, que fundem esperanças, utopias e mitos. (BACZKO, 1985, p. 325). A ideia de miscigenação, de uma democracia racial demonstrando uma unidade, além da possibilidade de se intitular os "melhores do mundo" a cada vitória de um time de futebol sugerem simbologias que se aderem de maneira eficaz aos desejos e às aspirações do futuro de uma nação. Para Baczko (1985), a grande mola propulsora da dinâmica do imaginário é a esperança e certeza da vitória próxima e fácil. Acreditamos que o esporte proporciona este simbolismo, principalmente nas visões jornalísticas de constantemente nos alçar ao posto de "melhores do mundo". Baczko ainda afirma que "os homens precisam de fatos, signos, imagens, gestos, figuras a fim de se comunicarem entre si e se reconhecerem" (BACZKO, 1985, p. 321). O simbolismo da Copa do Mundo no Brasil e seus ritos coletivos atuam nessa vertente, tornando-se um instrumento eficaz para regular e orientar a sensibilidade coletiva, influenciando comportamentos, fazendo o país vestir verde e amarelo durante a competição, num impulso patriótico cíclico a cada quatro anos. Logo, ela se torna um evento simbolicamente midiatizado ao articular signos facilmente reconhecidos e, assim, consegue sustentar a ação narrativa.

Aqui é pertinente trazermos as considerações de Paul Ricoeur

3 Aqui é meritório citar as recentes discussões sobre a diminuição da força da expressão "pátria de chuteiras", ocasionada por uma fragmentação das identidades no mundo pós-moderno. 
acerca da construção da narrativa. As ações de determinados atores sociais são contadas por meio do que Ricoeur (2010) chama de intriga. Em suma, a intriga pode ser entendida como a escolha de ações humanas que vão tornar a narrativa compreensível, com início, meio e fim e que lhe darão determinado sentido de acordo com o que é contado e aquilo que não é contado, por meio de escolhas e angulações. Deste modo, o que vai ser narrado, o que fica nos bastidores ou na fachada (GOFFMAN, 2007) e a ordem dos fatos direcionam o sentido da notícia e constroem o acontecimento jornalístico.

Também neste processo de escolhas, o imaginário será acionado e vai atuar junto com os simbolismos que o contexto da competição proporciona, produzindo sentidos para as ações que Ricoeur define "em função de". São essas articulações sociais de significação (imaginário e cultura) que atuam na produção simbólica e articulam todo o processo, criando situações sociais reconhecidas e compartilhadas. Como afirma Ricoeur: "se podemos falar da ação como um quase texto é na medida em que os símbolos, entendidos como interpretantes, fornecem as regras de significação em função das quais determinadas condutas podem ser interpretadas" (RICOEUR, 2010, p. 103). Resumindo, "em função da" Copa se fecham os estabelecimentos comerciais, amigos e familiares se reúnem para assistirem aos jogos, pintam-se ruas, prédios e corpos com as cores nacionais etc.

Além disso, o imaginário auxilia na estruturação dos enquadres que a Copa do Mundo molda na sociedade brasileira. Ao permitir um sistema de orientações expressivas e afetivas que remetem a estereótipos oferecidos aos agentes sociais, os imaginários sociais criam uma reciprocidade cultural entre narradores e receptores (BACZKO, 1985). Essa reciprocidade define situações comunicacionais necessárias para decifrar e dar sentido aos acontecimentos. Estamos falando de um suposto sentimento de tristeza coletiva com derrotas da seleção, por exemplo, já que na situação social partilhada e de fácil entendimento de todos, ela 
"nos representa". Essas molduras determinam, além de significados da vida cotidiana, os modos adequados de participar dela. Assim, se desenham maneiras de construir narrativas jornalísticas sobre a competição, de comportamentos esperados de jogadores e técnicos e formas de se torcer, criando a narrativa da "pátria de chuteiras".

Logicamente que tais construções precisam de subsídios para se manterem ativas. Édison Gastaldo (2002, p. 36) associa a ligação da cultura nacional com o futebol em grande parte pela participação brasileira nas Copas do Mundo. Após a Copa de 1938, competição que acreditamos ter germinado a íntima ligação seleção-nação, o país foi sede da Copa de 1950. Roberto DaMatta (1982) classifica a derrota na Copa de 1950 para o Uruguai como "uma tragédia nacional", argumento que aguça a importância que o evento ocupa no imaginário social do país. As vitórias em 1958, 1962, 1970 e a consequente conquista definitiva da Taça Jules Rimet, aliadas ao contexto de consolidação do país como Estado-nação, reforçaram a relevância do futebol para a nossa identidade nacional. O tricampeonato também alicerçou na narrativa midiática a ideia do futebol-arte como algo tipicamente nacional, e de que éramos indiscutivelmente os melhores do mundo neste esporte. Estes dois atributos seriam as principais bases que a representação "país do futebol" teria nos anos seguintes, exigindo não apenas a vitória da seleção, mas também o chamado jogo bonito, como algo particular do brasileiro, na "situação social" compartilhada sobre a Copa do Mundo.

As derrotas nas Copas de 1974 e 1978 foram narradas pela imprensa como fugas de "nossa essência", por conta do estilo de futebol classificado como "futebol-força". Era como se a equipe "abandonasse" a situação social já estipulada que exigia que a seleção praticasse um futebol voltado para suas "reais origens", baseado no drible, improviso, ofensividade e floreios com a bola. Ao fugir do frame já estabelecido, existe um estranhamento ao não se seguir o "papel” já conhecido. A forma com que a seleção da Copa de 1982 atuava foi considerada pela mídia um retorno às 
"raízes nacionais". Com este atributo, a expectativa de vencer a competição por conta de "executarmos o papel" de acordo com o script entendido como o correto foi grande. Este clima eufórico de confirmar nossa identidade com o "futebol ideal" e de conquistar o tetracampeonato influenciaram o tom de melancolia e surpresa da narrativa da derrota que a foto analisada representa.

\section{A Copa de 1982}

O otimismo no campo esportivo descrito acima se articulava com os acontecimentos em outras esferas, como a abertura política por meio da lei da Anistia, assinada pelo então presidente João Batista Figueiredo em agosto de 1979. Mais de quatro mil pessoas que estavam exiladas puderam voltar ao Brasil. Já em dezembro de 1979, a lei de organização partidária extinguiu o MDB e a ARENA, permitindo a criação de novos partidos com a implantação do pluripartidarismo.

Nesse contexto de abertura política e redemocratização, a Confederação Brasileira de Desportos (CBD) foi desmembrada em várias federações. Cada uma seria responsável por organizar e promover um esporte específico. Assim, no dia 29 de setembro de 1979 foi criada a Confederação Brasileira de Futebol (CBF). $\mathrm{O}$ antigo presidente Heleno Nunes entregou o cargo a Giulite Coutinho em 18 de janeiro de 1980. A ideia principal da nova direção era recuperar a hegemonia e o prestígio no futebol mundial praticando o "verdadeiro" estilo brasileiro, supostamente perdido nas Copas de 1974 e 1978. O técnico escolhido para essa missão foi Telê Santana.

Entendemos que o ano de 1981 foi importante para a recuperação desta confiança. A seleção fez, segundo a narrativa da imprensa, uma boa participação no Mundialito em Montevideo ${ }^{4}$,

4 O torneio foi uma comemoração dos 50 anos da primeira Copa do Mundo, disputada no Uruguai em 1930. Participaram da competição Uruguai, Itália, Argentina, Brasil, Alemanha e Holanda. 
apesar de perder para o Uruguai na final por 2 a 1. Depois dessa derrota, foram 19 jogos até a estreia na Copa do Mundo: quatro empates e quinze vitórias. A seleção embarcou para disputar uma Copa como favorita, com o apoio da população, que acreditava no título. Mais de duas mil pessoas foram se despedir da equipe no Aeroporto do Galeão. Novamente o futebol aparecia como o fio condutor do momento de reafirmação do brasileiro pelo seu país e pelas cores nacionais. As ruas foram pintadas de verde e amarelo, sem medo de se remeter ao regime militar. Até uma canção, composta e interpretada pelo lateral Júnior, embalava a população e se tornaria símbolo da nossa seleção. Não era uma marchinha que seria repudiada por alguns setores como "Pra frente Brasil", de 1970, mas um sambinha chamado "Povo feliz", popularmente conhecido como "Voa canarinho, voa", que acreditava no sucesso da equipe na Copa da Espanha (GUTERMAN, 2009).

Destacamos este trecho da coluna Bola Dividida, de Sandro Moreyra, como um resumo da euforia presente nas narrativas midiáticas:

Desta vez há motivos de sobra para essa euforia que domina o país que, segundo nos contam os que daí chegam, está todo em festa, embandeirado e pronto para explodir na alegria das vitórias. E há motivos porque desde 1970, quando ganhamos o terceiro título, a Seleção Brasileira não reúne uma equipe tão cheia de craques, nem se preparou de forma tão bem organizada. Os jogadores que logo mais entrarão em campo para enfrentar os soviéticos são os que nosso futebol possui de melhor no momento (JORNAL DO BRASIL, 14/06/1982, p. 9).

A estreia foi com vitória em cima da URSS por 2 a 1 . O resultado foi comemorado pela imprensa, que destacou o retorno do futebol-arte brasileiro. No segundo jogo, outra exibição classificada como típica de "nossa escola de futebol", vitória 
por 4 a 1 em cima da Escócia. O último jogo da primeira fase da competição corroborou a ideia do estilo nacional resgatado por esta seleção: a equipe venceu a Nova Zelândia por 4 a 0 . O Brasil apresentava um futebol baseado no ataque (dez gols em três jogos), cometendo poucas faltas e, por isso, passou a ser enaltecido não só pela imprensa nacional, mas também pela imprensa internacional.

$\mathrm{Na}$ segunda fase, a equipe enfrentou Argentina e Itália. O primeiro jogo colocou em confronto aqueles considerados "os dois maiores jogadores do mundo" na época: Zico e Maradona. O brasileiro levou vantagem, atuando de forma decisiva na vitória por 3 a 1 do Brasil. Do outro lado, Maradona desapontou os argentinos sendo expulso de campo. A seleção fez, para a imprensa, uma exibição de gala e venceu nosso principal rival e atual campeão do mundo. Por conta do saldo de gols, um empate contra os italianos colocaria a seleção nas semifinais de uma Copa que para muitos já tinha um campeão: o Brasil. Este trecho da coluna do jornalista Sandro Moreyra do Jornal do Brasil, logo após a partida, resume o sentimento da imprensa nacional:

\begin{abstract}
A seleção Brasileira demonstrou mais uma vez a sua imensa superioridade. Tecnicamente, é o time mais bem esquematizado e individualmente o que possui os craques de mais alta categoria. Este time - repetimos a tese que vimos defendendo desde o início - tem tudo para ganhar a Copa, até sem dificuldades maiores. Só perde por um acidente, um absurdo igual, por exemplo, ao que aconteceu na Copa de 50 com o Brasil. Fora daí, nem mesmo um complô de árbitros pode nos tirar o título (JORNAL DO BRASIL, 03/07/1982, p. 11).
\end{abstract}

A ideia de que apenas uma tragédia, como em 1950, retiraria o título da seleção foi dominante nas narrativas jornalísticas. Os italianos vinham de três empates seguidos na primeira fase e uma vitória definida como "sem muito brilho" sobre os argentinos. Nesta 
conjuntura a seleção chegou ao jogo contra a Itália com um amplo favoritismo da mídia nacional e internacional. Acreditamos que, ao enquadrar e escolher essa linha narrativa, a imprensa influencia (não determina) a relação de afeto e a expectativa do torcedor com a equipe, construindo uma "verdade" de que "somos os favoritos". Esse discurso será determinante no clima de tristeza ocasionado pela derrota, frustrando a perspectiva de vitória.

\section{Nossa segunda "tragédia nacional”?}

Em um jogo definido pelas narrativas jornalísticas como histórico e espetacular, a seleção perdeu por 3 a 2. Na primeira página do caderno de Esportes do Jornal do Brasil do dia 6 de julho, a dicotomia entre alegria e tristeza ficou evidente com fotos de rostos do contraste dos torcedores brasileiros e italianos seguidas pelos títulos: "O amargo sabor da derrota" e "A doce alegria da vitória". $\mathrm{Na}$ página quatro, todas as reportagens falavam da desolação da torcida brasileira. As narrativas enfatizavam a decepção, a tristeza e o choro. Já a coluna de Sandro Moreyra começou fortalecendo a narrativa de que a derrota foi uma surpresa e recuperou a memória de outros resultados considerados surpreendentes em Copas do Mundo:

A seleção de melhor futebol da Copa, apontada por todos como franca favorita para a conquista do título, foi derrotada pela Itália de forma inapelável. O que aconteceu ontem, aqui em Barcelona, entrará para a história do futebol, como o 16 de julho de 50, no Maracanã, ou a derrota na Copa de 54, da famosa Seleção Húngara. São dessas surpresas que o futebol de vez em quando apresenta e que talvez por isso o torne o esporte fascinante que é. Nem sempre a melhor equipe fica com o título (JORNAL DO BRASIL, 06/07/1982, p. 9). 
O meio-campo Falcão deu entrevistas após a partida e, segundo o jornal O Globo, "as palavras tinham um tom dramático, como a justificar o vermelho dos olhos, sintoma evidente de muito choro" (O GLOBO, 06/07/1982, p. 2). A coluna Papo de esquina, de Sérgio Cabral, com o título "Aqui entre nós: foi uma derrota bem brasileira" (O GLOBO, 06/07/1982, p. 2), fala da dificuldade de explicar a derrota da seleção e imprime um sentido interessante ao afirmar que não estava arrependido, apenas triste, por termos perdido praticando o que seria o nosso "verdadeiro futebol".

Na página três do jornal O Globo, encontramos o olhar de outros países sobre a nossa derrota. As narrativas mantêm a mesma linha, corroborando as apresentadas pelos jornais nacionais. "Até a Espanha inconformada: Copa foi injusta e perversa", estampou o jornal Correo Catalan, que exaltava a "perplexidade da imprensa espanhola com a eliminação do Brasil e o pesar da ausência nas finais do futebol que consideravam o mais alegre, o mais requintado e o mais empolgante da Copa do Mundo" (O GLOBO, 07/07/1982, p. 3). O L'Equipe da França destacou: "Brasil era melhor, não podia perder o Mundial, mas hoje chora a derrota, como resultado de uma partida notável, que demonstrou outra vez que os italianos podem realizar um ótimo jogo quando assim o decidem" (O GLOBO, 07/07/1982, p. 3). O Diário de Notícias de Portugal falou: "Apesar da justiça da vitória italiana, nada destruirá uma verdade: foi uma injustiça ver-se descer o pano sobre o melhor futebol, o mais refinado espetáculo deste Mundial". Entendemos aqui que, novamente, os jornais reproduzem e escolhem as manchetes apropriadas para corroborar suas narrativas.

Leda Costa (2014) afirma que "a derrota para a Itália foi nossa segunda tragédia, a tragédia de Sarriá, como ficou conhecida" (COSTA, 2014, p. 165-166). Segundo a autora, os questionamentos da derrota de 1982 foram bem próximos aos da derrota de 1950, que buscavam responder "como isso pode acontecer?" com respostas que encenavam "um embate entre forças humanas e forças do destino" (COSTA, 2014, p. 166). A autora sugere que 
a imprensa esportiva nacional busca interpretar sentidos de uma derrota da seleção nacional por outros motivos que não o esportivo. Ela cita o empenho por achar culpados em 1950 e em outras Copas do Mundo, entretanto afirma que, em 1982, "as respostas dadas à pergunta 'por que perdemos?' não tiveram como prioridade a caça a culpados, nem a tentativa de desmerecer a seleção e seus jogadores" (COSTA, 2014, p. 176). O contexto apresentado creditava à seleção nacional, mais uma vez, a cristalização de um país que retomava suas "raízes" por meio da representação do futebol-arte. Segundo Costa:

havia um aparato discursivo que colocava em circulação uma série de representações e significados que iam sendo anexados àquela seleção. Representações relacionadas ao futebol-arte, tão caro à imagem e à autoimagem do futebol brasileiro. A seleção de 1982 foi compreendida por muitos como aquela que traria de volta um futebol especial (COSTA, 2014, p. 180).

Entendemos que, em geral, a narrativa se baseou em explicar a eliminação sem procurar culpados, construindo um discurso de catástrofe, tragédia, tristeza, choro, injustiça e imponderável. Estes sentidos serão decisivos na articulação dos significados que a fotografia analisada irá evocar.

\section{Contextos e articulações na produção de sentidos}

\section{na "imagem da derrota"}

Seguindo as ideias de Gregory Bateson (1986) destacamos que todos os elementos de um sistema estão interligados e contribuem para a formação de contextos, influenciando diretamente o desenvolvimento da comunicação de quem está inserido neste sistema. Acreditamos que cultura, imaginário, representações e 
identidades se articulam e interagem constantemente. Para analisar uma fotografia devemos considerar todas essas articulações e elementos que darão o norte discursivo que a imagem simboliza. Uma imagem pode ter vários sentidos; o contexto ou a situação social no qual ela é produzida é que articulará seu significado, minimizando possíveis dubiedades no processo comunicacional, já que elas não podem ser totalmente descartadas. Para que a comunicação seja eficaz é necessário que todos os participantes compartilhem do mesmo simbolismo. Neste sentido, acreditamos que a Copa do Mundo cumpre este papel pelos motivos já elencados. Para Bateson (1986), as partes que se comunicam precisam manter certas verdades para que a interação ocorra e essas verdades são construídas a partir da articulação com experiências anteriores. Ou seja, contextos anteriores já familiares aos indivíduos fazem com que a compreensão de comportamentos e ações seja mais rápida, facilitando a comunicação e a produção de sentidos, no nosso caso sobre a Copa do Mundo e as vitórias e derrotas da seleção. A comunicação humana, segundo Bateson (1986), é realizada tentando conectar imagens presentes no imaginário do indivíduo e o mundo exterior. O imaginário e a situação social sobre a Copa do Mundo se articulam com as identidades e sentimentos provocados por conta de uma derrota estipulada na narrativa midiática como trágica. A ideia de código de Bateson (1986) nos esclarece esta situação ao indicar que os participantes de uma determinada cultura comunicam não só um conteúdo, mas também instruções de como interpretar uma determinada mensagem.

Bateson (1986) define este processo como "aprender a aprender", o que seria aprender dentro de determinado contexto, regras e estipulações. Quando se aprende a interagir dentro de um determinado contexto, fica mais fácil e rápido lidar com as articulações, pois aquele processo já se tornou familiar ao sujeito. Isso faz com que se compreendam melhor os comportamentos e as ações dos indivíduos no contexto de Copas do Mundo. Essa concepção já clarifica as possibilidades de entendimento da 
fotografia no contexto da competição.

É o que também nos aponta Joly (2006), ao enfatizar que apesar da diversidade de significados de uma imagem, nós a compreendemos por sermos intrinsecamente e culturalmente iniciados na compreensão de imagens. Esta compreensão se baseia no entendimento de que ela designa algo (o sentimento provocado pela derrota brasileira). Em suma, a descrição e representação do "mundo real" por meio da fotografia estimulam sentidos para aquela sociedade que partilha os mesmos mapas culturais.

A foto ganhou o "Prêmio Esso" daquele ano, uma das maiores premiações do jornalismo nacional. O próprio site do prêmio resume desta forma a fotografia: "o dia em que o Brasil perdeu para a Itália por 3 a 2, deixando escapar, na Espanha, o título de tetracampeão mundial de futebol, foi de tristeza nacional. O menino chorando era o retrato de 120 milhões de brasileiros, naquele instante"5.

O garoto da fotografia é José Carlos Villela Júnior, na época com dez anos. O contexto da produção desta imagem é importante para corroborar alguns argumentos que vamos elucidar mais adiante. José foi com a família, a convite da FIFA, assistir à Copa do Mundo. $\mathrm{O}$ autor da foto revela que ao ver na arquibancada o menino chorando ao lado da mãe, fez vários "cliques" dos dois. Entretanto nenhuma lhe agradou por conta do choro excessivo do menino. Reginaldo relata que esperou o momento em que o garoto soluçava e voltaria a mais uma crise de choro para enquadrá-lo sozinho na imagem que simbolizaria o sentimento da derrota para a Itália. O editor do Jornal da Tarde, Mário Marinho, recebeu cerca de 20 fotos de Reginaldo e explica por que escolheu aquela imagem:

Não dava para simplesmente dizer 'a seleção perdeu para a Itália com três gols de Paolo Rossi'. A gente precisava de um diferencial. É um choro, mas repare como ele tem o peito estufado, o nariz empinado, o gesto típico de quem tem orgulho da camisa que veste. A foto é uma poesia. Pais

5 Disponível em: <http://www.premioexxonmobil.com.br/site/premio_ principal/index.aspx?year=1982> . Acesso em: 26 maio 2016. 
e mães viam naquele menino o sofrimento dos seus filhos depois do jogo (MARINHO apud WILKSON, 2012).

Vimos que a própria fala do editor que escolheu a foto para ser a capa do jornal auxilia no argumento de que a imagem engloba os elementos que abordamos anteriormente. Sua dinâmica de construção de sentidos dada pelo modo com que os elementos presentes no contexto se relacionam vão colocá-la na narrativa jornalística como símbolo daquela derrota.

A imagem de um menino chorando com a camisa do Brasil poderia ser vista como "normal" fora do contexto da Copa do Mundo e de todos os fatores que mobilizaram milhões de brasileiros a acreditar naquela equipe. Cada contexto produz um sentido diferente, ou para ser mais preciso: "com a fotografia, não nos é mais possível pensar a imagem fora do ato que a faz ser" (DUBOIS, 1993, p. 15). A imagem nos permite construir sentidos que serão estruturados a partir de sua relação com outros fatos que a circundam e influenciaram sua concepção.

Uma imagem, toda imagem, resulta dos movimentos provisoriamente sedimentados ou cristalizados nela. Esses movimentos a atravessam de fora a fora, e cada qual tem uma trajetória - histórica, antropológica, psicológica - que parte de longe e continua além dela. Eles nos obrigam a pensá-la como um momento energético ou dinâmico, ainda que ele seja específico em sua estrutura (DIDI-HUBERMAN, 2013, p. 33).

Podemos afirmar que o choro do garoto foi um momento específico no contexto que construiu o sentido da derrota brasileira. Este "quadro", este momento "estático" capturado pela câmera do fotógrafo funciona como um símbolo de toda a articulação simbólica que imaginário, representação, contexto e narrativas que a Copa do Mundo propicia, além de nos indicar para onde se deve dirigir o 
olhar. Seguindo o pensamento de Flusser (2002), concordamos que a imagem é um processo conceitual. Ao se fazer uma foto, já se olha com um filtro, com aquilo que se pensa, a realidade de quem fez. No caso da foto analisada no artigo, a história de sua produção descrita anteriormente confirma a nossa reflexão. Manente procurava uma imagem que demonstrasse a tristeza da torcida nacional, era a intenção narrativa do fotógrafo naquele momento. Além disso, o fato de esperar o "momento certo" para clicar o menino engolindo as últimas lágrimas e, como Manente mesmo disse, esperá-lo chorar mais uma vez, demonstra que o foco pretendido para o sentido daquele momento foi, realmente, produzido. A imagem se torna, assim, uma forma de pensamento, exatamente por relacionar conceitos como alegorias do objeto. Também é profícuo trazermos Latour (2009) para o debate, principalmente sua argumentação de que a técnica ${ }^{6}$ funciona para fazer algo chegar a determinado resultado. Estamos falando da construção da imagem de um fato a partir do muito de humano que há na técnica (tecnologia) e muito de técnico que há no humano, dentro do processo de construção que o autor chama de redes. Para Latour, esta relação da produção da fotografia - seria um encontro da técnica do fotógrafo (e recursos da câmera) - com a prática social de retratar o que aconteceu será entendida como o "híbrido sociotécnico" da imagem.

Tal pensamento nos sugere que mesmo sem saber que fez, sendo consciente ou não, o fotógrafo Manente, ao realizar a foto do menino José, estava impregnado do contexto que o levou a escolher aquele momento, ou seja, aquele recorte. Ao ser escolhida como capa do jornal, a imagem condensa o que será transmitido dentro de um contexto temporal. Ela se torna capa pelos princípios da organização jornalística, por sedimentar os registros que englobam o que se aspira que seja entendido pelos leitores, indicando a intenção da narrativa do jornal. O menino chorando é uma rede de relações que tem um sentido plural e amplo dentro do contexto

$6 \quad$ Neste caso entendemos a técnica segundo Simondon (1999), como algo que vai mediar a relação homem-mundo. 
que envolveu o sentimento da derrota da Copa de 1982. Seu rosto é o rosto de uma situação, um rosto coletivo, é o rosto que engloba toda a experiência em questão, enfim, é uma máscara que expressa o choro coletivo.

A fotografia também funciona como um ato em que se produz uma memória do momento, um pensamento, o significado daquele acontecimento. É criada uma cena, um recorte, uma representação de um momento repleto de sentidos. Assim, entendemos que a imagem possui também um jogo duplo. Ela organiza e é organizada pelo discurso, pelo contexto e pela situação. Ao mesmo tempo em que entendemos que a imagem não possui "a verdade", sabemos que ela traz um fato concreto (o menino chorou), ou seja, o momento em que ela foi feita representa um momento que realmente existiu. Tal fato nos assombra e nos fascina, principalmente, por imortalizar um momento específico. Todas as vezes que olharmos a capa do Jornal da Tarde do dia 6 de julho de 1982 nos lembraremos do instante em que o menino José chorou a derrota brasileira em Barcelona. Como afirma Dubois (1993), a fotografia flutua na certeza:

Com efeito, de todas as artes da imagem, a fotografia é, com certeza, aquela em que a representação está ao mesmo tempo, ontologicamente, mais próxima de seu objeto, pois ela é sua emanação física direta (a impressão luminosa) e porque ela the cola literalmente na pele (estão intimamente ligados), mas é igualmente e também ontologicamente aquela em que a representação mantém absolutamente a distância com o objeto, em que o coloca, obstinadamente, como um objeto separado. Essa separação chega a fundamentar literalmente toda a dinâmica do jogo fotográfico: é ela que induz esse movimento constante, esses perpétuos vaivens do sujeito espectador, que não para, do ponto de vista da foto, de passar do aqui-agora da imagem ao alhuresanterior do objeto, que não para de olhar intensamente essa imagem bem presente (DUBOIS, 1993, p. 348). 
A imagem que analisamos produz este jogo descrito por Dubois. O menino está lá, distante, como algo separado do presente e ao mesmo tempo pode nos remeter ao passado. Vê-la é voltar no tempo, se aproximar da "tragédia do Sarriá", recuperar na memória o sentido daquela derrota. O sujeito espectador acaba se vendo naquele dia, reativando seus afetos vividos no dia 5 de julho de 1982, adornando a relação esporte e fã. Dessa forma, José simboliza muito mais do que um garoto chorando, ele é a "cara" da narrativa da derrota que articulou os elementos que apresentamos ao longo do texto.

\section{Considerações Finais}

A ligação seleção e nação edificada nos anos 1930 se tornou uma associação facilmente identificada na sociedade brasileira e explorada pela imprensa ao longo das décadas. A identidade nacional, fator de reconhecimento entre os indivíduos, e os mapas culturais e enquadramentos elaborados neste processo articularam contextos que propiciaram sentimentos de alegria e tristeza nas vitórias e derrotas da seleção como algo "nacional". Estes afetos estabelecem uma ligação robusta com o imaginário nacional durante as Copas do Mundo e tornam o evento algo recheado de nacionalismo, desejos e paixões. Após a derrota de 1950, a conquista do tricampeonato atribuiu o nosso sucesso a um estilo tipicamente nacional, surgindo na narrativa midiática a pretensão de que quando jogamos assim, vencemos sempre.

A seleção de 1982 é narrada na mídia como o time que reestabeleceria este elo com as seleções vitoriosas, exatamente por exercer a "nossa identidade futebolística". O otimismo inicial encontrou na eliminação precoce da competição para a Itália o resgate de outra situação social já reconhecida: a "tragédia de 1950". A narrativa midiática de eventos esportivos se apoia nestes afetos e em buscas a passados similares na tentativa de estabilizar 
sentidos sobre os resultados. Nesta tentativa de enquadres que tornam a comunicação mais simples, a imagem emerge como uma sintetizadora de toda essa articulação. Imagens de atletas funcionam como símbolos de determinados esportes e seleções, como Pelé, Garrincha e Maradona. No nosso caso, a "dor nacional" pela derrota, mas com o "peito estufado" por praticar o "nosso estilo" teve como ícone a fotografia analisada. O choro de José é subentendido pelo código e pelo contexto da situação. Ao verem a capa do jornal no dia seguinte todos sabiam em quais circunstâncias e por qual motivo o garoto chorava. Esse discurso das imagens como "frames" de contextos simbolizam mapas culturais e situações sociais que serão facilmente entendidos para quem compartilha deles. Em suma, nosso olhar "chega pronto" com os códigos articulados no contexto. Além disso, ao ir para a capa de um jornal, a fotografia se torna um grande símbolo do momento. A imagem trabalha, assim, em um jogo duplo, no qual a foto não precisa ter legenda, o sentido já está construído pela articulação da situação, do comportamento do menino, do modo de registro, da intenção do fotógrafo e do editor, ou seja, a imagem é o "texto" na capa analisada, ela "fala" por meio dessas articulações. Acreditamos que a linguagem visual articula o contexto, o meio de comunicação, o imaginário, as identidades e os mapas culturais estabelecidos entre emissor e receptor, possibilitando a idealização de sentidos e, no caso do esporte, estimulando o afeto do torcedor com seu objeto de adoração.

\section{Referências}

BACZKO, Bronislaw. A imaginação social. In: LEACH, Edmund et al. Anthropos-Homem. Lisboa: Imprensa Nacional/Casa da Moeda, 1985.

BATESON, Gregory. Mente e natureza: a unidade necessária. São Paulo: Francisco Alves, 1986. 
COSTA, Leda. 1982: lágrimas de uma geração de ouro. In: HELAL, Ronaldo; CABO, Álvaro (Orgs.). Copas do Mundo: comunicação e identidade cultural no país do futebol. Rio de Janeiro: EdUERJ, 2014.

DaMATTA, Roberto. Universo do futebol: esporte e sociedade brasileira. Rio de Janeiro: Pinakotheke, 1982.

DIDI-HUBERMAN, G. A imagem sobrevivente. Rio de Janeiro: Contraponto, 2013.

DUBOIS, Philippe. O ato fotográfico. São Paulo: Campinas: Papirus, 1993.

DURAND, Gilbert. As estruturas antropológicas do imaginário: introdução à arquetipologia geral. Lisboa: Ed. Presença, 1997.

FLUSSER, Vilém. Filosofia da caixa preta. Rio de Janeiro: Relume Dumará, 2002.

FREYRE, Gilberto. Casa grande \& senzala: formação da família brasileira sob o regime patriarcal. Recife: Global Editora, 2003.

GASTALDO, Édison. Pátria, chuteiras e propaganda: o brasileiro na publicidade da Copa do Mundo. São Paulo: Annablume, 2002.

GOFFMAN, Erving. Frame analysis: An essay on the organization of experience. Harvard University Press, 1986.

A representação do eu na vida cotidiana. Tradução de Maria Célia Santos Raposo. Petrópolis: Vozes, 2007.

GUEDES, Simoni Lahud. Futebol e identidade nacional: reflexões sobre o Brasil. In: DEL PRIORE, Mary; MELO, Victor Andrade 
de. (Orgs.) História do esporte no Brasil: do império aos dias atuais. São Paulo: Editora UNESP, 2009.

GUTERMAN, Marcos. O futebol explica o Brasil: uma história da maior expressão popular do país. São Paulo: Contexto, 2009.

HALL, Stuart. A identidade cultural na pós-modernidade. Tradução: Tomaz Tadeu da Silva. Rio de Janeiro: DP\&A Editora, 2011.

JOLY, Martine. Introdução à análise da imagem. Campinas: Papirus, 2006.

JORNAL DO BRASIL, Rio de Janeiro, 14 jun./06 jul., 1982.

LATOUR, Bruno. Jamais fomos modernos. 2. ed. Rio de Janeiro: Editora 34, 2009.

LE GOFF, Jacques. L'imaginaire medieval. Paris: Gallimard, 1985.

MOSCOVICI, Serge. Representações sociais: investigações em psicologia social. Tradução: Pedrinho A. Guareschi. 9. ed. Petrópolis: Vozes, 2012.

O GLOBO, Rio de Janeiro, 06 jul./07 jul., 1982.

RICOEUR, Paul. Tempo e narrativa. São Paulo: Martins Fontes, 2010 .

SARMENTO, Carlos Eduardo Barbosa. A construção da nação canarinho: uma história institucional da seleção brasileira de futebol, 1914-1970. Rio de Janeiro: Editora FGV, 2013. 
SIMONDON, Gilbert. Du mode d'existence des objets techniques. Paris: Aubier, 1999.

SODRÉ, Muniz. A narração do fato: notas para uma teoria do acontecimento. Petrópolis: Vozes, 2009.

. As estratégias sensíveis: afeto, mídia e política. Petrópolis: Vozes, 2006.

WILKSON, Adriano. No fim do Jornal da Tarde, menino da tragédia do Sarriá conta como foto histórica marcou sua vida. UOL, São Paulo, 31 out. 2012. Seção Esporte. Disponível em: <http:// esporte.uol.com.br/futebol/ultimas-noticias/2012/10/31/meninoda-tragedia-do-sarria-lamenta-fim-de-jornal-tarde-e-conta-comofoto-historica-marcou-sua-vida.htm>. Acesso em: 23 out. 2013. 